\title{
Adult reversal of cognitive phenotypes in neurodevelopmental disorders
}

\author{
Alcino J. Silva • Dan Ehninger \\ Received: 1 April 2009 /Accepted: 18 May 2009/Published online: 17 June 2009 \\ (C) The Author(s) 2009. This article is published with open access at Springerlink.com
}

\begin{abstract}
Recent findings in mice suggest that it is possible to reverse certain neurodevelopmental disorders in adults. Changes in development, previously thought to be irreparable in adults, were believed to underlie the neurological and psychiatric phenotypes of a range of common mental health problems with a clear developmental component. As a consequence, most researchers have focused their efforts on understanding the molecular and cellular processes that alter development with the hope that early intervention could prevent the emergent pathology. Unexpectedly, several different animal model studies published recently, including animal models of autism, suggest that it may be possible to reverse neurodevelopmental disorders in adults: Addressing the underlying molecular and cellular deficits in adults could in several cases dramatically improve the neurocognitive phenotypes in these animal models. The findings reviewed here provide hope to millions of individuals afflicted with a wide range of neurodevelopmental disorders, including autism, since they suggest that it may be possible to treat or even cure them in adults.
\end{abstract}

Keywords Neurodevelopmental disorders · Autism · Animal models $\cdot$ Rescue $\cdot$ Treatment

Neurodevelopmental disorders encompass a diverse and large group of disorders that not only affect developmental processes, but also include various pathologies that extend

\footnotetext{
A. J. Silva $(\bowtie) \cdot$ D. Ehninger $(\bowtie)$

Departments of Neurobiology, Psychiatry \& Biobehavioral

Sciences, Psychology and the Brain Research Institute,

University of California,

695 Charles Young Drive South,

Los Angeles, CA 90095-1761, USA

e-mail: silvaa@mednet.ucla.edu

e-mail: dehninger@mednet.ucla.edu
}

into adulthood. Neuropsychiatric phenotypes, such as autism, specific learning disabilities, ADHD, intellectual disability and epilepsy are often associated with this class of disorders. A plethora of genetic mutations and environmental factors (e.g., infections, immune dysfunction, intoxication, endocrine and metabolic dysfunction, nutritional factors, trauma, etc.) have been implicated in neurodevelopmental disorders. This review will focus on neurodevelopmental disorders with a clear genetic origin, such as tuberous sclerosis (TSC) and neurofibromatosis type I (NF1); However, the basic principle that adult intervention may ameliorate or even cure this large class of diseases may also apply to neurodevelopmental disorders without an obvious genetic contribution. An earlier version of this review was previously published [1].

\section{The long-term impact of disrupting neurodevelopmental processes}

There is a considerable amount of evidence suggesting that alterations in neurogenesis, cell migration, neuronal connectivity and in other developmental processes cause neurological, psychiatric and cognitive deficits in adults. For example, changes in the structure of specific brain regions during development have been suspected to underlie neurodevelopmental disorders. Development is an especially vulnerable stage where insults that have only minor repercussions in adults can cause profound pathologies. For example, mutations leading to phenylketonuria have serious effects during development, but stopping treatment results only in mild phenotypes in adults [2]. Similarly, untreated congenital hypothyroidism can lead to profound and irreversible cognitive deficits, while hypothyroidism in adults has milder effects on cognitive 
function [3-6]. Although development may be an especially fragile period, there are also examples of manipulations that result in far more serious effects in adults than in development. For example, trauma, infection, and ischemia may have much of the same or even more serious consequences in adults than during development $[7,8]$.

Animal studies have also shown that genetic disruptions with mild or no consequences in adults lead to serious functional disruptions when these disruptions are carried out during development, including postnatal development. Recently, a study with a carboxyl terminal end of the disrupted in schizophrenia 1 (Discl) gene showed that a brief (6-12 h) induction of a dominant negative mutant Discl allele during postnatal day 7 of development [9], but not in adults, is sufficient to trigger many phenotypes relevant for schizophrenia. This included deficits in working memory, social interaction, depression-like behaviors and neuronal structure [9], demonstrating that a carboxy-terminal portion of this protein modulates processes at post-natal day 7 that are critical for normal behavior in adults.

A carboxy-terminal portion of the Disc1 protein was regulated by fusing it with a mutant form of the estrogen ligand binding domain that does not bind estrogen but that instead binds tamoxifen [9]. The transgenic fusion protein stays inactive in the cell until tamoxifen is given to the mice [9]. Tamoxifen binds to the ligand binding domain of the fusion protein, changes its conformation and excludes heat shock proteins bound to the ligand binding domain; These heat shock proteins prevent the transgenic fusion protein from interfering with binding between Disc1 and its partners, such as Nudel [9]. Thus, addition of tamoxifen frees the transgenic carboxy-terminal portion of the Disc1 in the fusion protein to disrupt normal Disc1 function [9]. These results showed that interactions between the carboxyterminal portion of Disc1 and other proteins, such as Nudel, during postnatal development are critical for several behaviors disrupted in schizophrenia.

Interestingly, there is also evidence that Disc1 in the adult brain has a role in behavior [10]. Recent findings suggest that the amino terminal fragment of Disc1 binds to and regulates Gsk3beta function in the dentate gyrus of adult mice [10]. Knocking down of Disc1 in mice leads to hyperlocomotion in response to novelty, and higher depression-like behaviors in the forced swim test [10]. Importantly, treating the adult Disc1 mutant mice with a specific chemical inhibitor of Gsk3 (SB-216763) reversed both the hyperlocomotion and depression-like phenotypes of these mutants, sugesting that a decrease in Disc1 function in adult mice leads to higher Gsk3 activity and that this plays a critical role in these interesting behavioral phenotypes.

In contrast, the studies described above with an inducible dominant negative Disc1 protein fragment, that disrupted protein interactions specifically with the carboxy-terminal portion of Disc1 in the adult brain, did not affect depressionlike behaviors in the forced swim test [9]. However, as stated above, induction of this dominant negative Disc1 protein fragment during day 7 of development did affect performance in this behavioral model of depression [9]. As indicated above, the Gsk3 experiments demonstrate that adult interactions between Gsk3 and the N-terminal portion of Disc1 are critical for function in this same behavioral model of depression [9]. This indicates that a gene causing schizophrenia (Disc1), a neurodevelopmental disorder, has effects both in development and in adults.

Similar to DISC1, other genes associated with developmental disorders are also expressed in the adult brain. Thus, beyond any effects on development, disruptions of these genes in the adult brain may also contribute to phenotypes observed in adult individuals. A tantalizing possibility is that the loss of function of these neurodevelopmental genes may prevent functional recovery in adults, and that rescuing gene function in adults may allow latent neurodevelopmental processes to compensate for developmental deficits. Accordingly, several recent studies with mouse models demonstrate that adult expression of neurodevelopmental genes make a significant contribution to cognitive function. These findings showed that reversing the disruptions in molecular and cellular function specifically in adults can result in clear behavioral improvements.

\section{A ray of hope: reversing cognitive deficits in adults}

There are now a number of compelling examples, in mice, of rescue of neurocognitive deficits associated with developmental disorders in adults, including NF1, TSC, Down syndrome, Rubinstein-Taybi syndrome (RTS), Fragile X syndrome (FXS), and Rett syndrome.

Ras-dependent activation of Mitogen Activated Protein Kinase (MAPK) has a key role in synaptic plasticity as well as learning and memory, and disruptions in this signaling pathway underlie a number of genetic disorders that affect cognitive function. For example, mutations in the Neurofibromatosis type $1(N F 1)$ gene, encoding neurofibromin, a p21Ras GTPase Activating Protein (GAP), cause learning disabilities, including difficulties with visuo-spatial skills, memory and attentional-executive function deficits. These neurocognitive phenotypes can be effectively modeled in mice with a heterozygous null mutation of the $N f 1$ gene $\left(\mathrm{NfI}^{+-}\right)$[11, 12]. Recent studies have shown that the learning and memory deficits of $\mathrm{NfI}^{+/-}$mice are caused by excessive Ras/Mapk signaling leading to hyperphosphorylation of synapsin I, and subsequent enhancements in GABA release, which in turn result in impairments in the induction of long-term potentiation (LTP), a cellular 
mechanism of learning and memory [13, 14]. Accordingly, a brief intervention specifically in adults with the farnesyltransferase inhibitor BMS 191563 [13] reversed the biochemical, electrophysiological and behavioral phenotypes of the $\mathrm{Nfl}^{+/-}$mice. BMS 191563 decreases the levels of active Ras by decreasing farnesylation and therefore the membrane associated form of this signaling molecule. Similarly, acute treatment with a low dose of a $\mathrm{GABA}_{\mathrm{A}}$ antagonist (picrotoxin), ineffective in controls, could also reverse the LTP and learning deficits of adult $\mathrm{NfI}^{+-}$mice [14]. Importantly, the doses of BMS 191563 and picrotoxin used in these studies reversed the learning deficits in $\mathrm{Nf}^{+/-}$ mice but did not change learning in wild-type control mice. These results demonstrate that the treatments used targeted the mechanisms specifically affected in the mutant mice.

Recent studies found that statins are a potent inhibitor of Ras/Mapk activity in the brain. Importantly, at concentrations ineffective in controls, statins reversed the enhanced Ras activity in the brain of $\mathrm{Nf}^{+/-}$mice, rescued their LTP deficits, and reversed their spatial learning and attention impairments [12]. Strikingly, recently completed pilot clinical trials [15] uncovered suggestive evidence that statins may also be able to reverse some cognitive deficits in children with NF1. Although a short 12-week statin treatment did not have a significant overall impact on the cognition of NF1 patients, it did reverse impairments in an object assembly test [15]. It is also worth noting that the treatment impacted only object assembly scores of those NF1 individuals with poor performance, while having no effect on patients with normal performance at the start of the trial. Currently ongoing trials with more patients and with longer treatments may determine whether statins have a beneficial impact on the cognition and, more importantly, quality of life of NF1 patients. There have been reports that suggest that NF1 patients are affected by other neurological and psychiatric symptoms, such as higher rates of autism and epilepsy. It will be important to determine if these and other symptoms are also ameliorated by treatment with statins. Interestingly, beyond NF1, a number of other neurodevelopmental disorders also seem to be associated with enhanced inhibition, including Down syndrome.

Elegant studies with Ts65Dn mice [16], an animal model of Down syndrome, also revealed LTP and learning deficits that appear to be caused by enhanced GABAergic inhibition $[17,18]$. Down syndrome, a result of trisomy of chromosome 21, is the most common genetic cause of intellectual disability. The Ts65Dn mice include a partial triplication of chromosome 16, the mouse homologue to human chromosome 21 . The vast majority of studies on this genetic condition were previously focused on identifying and studying the developmental implications of the many genes triplicated in trisomy 21 , since this disorder has a clear onset during development. However, a recent study
[18] demonstrated that the LTP and learning impairments of Ts65Dn mice could be reversed by manipulations that decrease GABAergic inhibition. Chronic, but not acute, doses of pentylenetetrazole (PTZ), picrotoxin and bilobalide, three different $\mathrm{GABA}_{\mathrm{A}}$ receptor antagonists, were shown to reverse deficits in object recognition in adult Ts65Dn mice [18]. Amazingly, these effects persisted up to 2 months following PTZ treatment; accordingly, studies of LTP showed that PTZ-treated Ts65Dn mice demonstrated improvements in LTP up to 3 months after the end of treatment [18]. A recent study from another group confirmed that a 7-week treatment with the $\mathrm{GABA}_{\mathrm{A}}$ receptor antagonist pentylenetetrazole reversed spatial learning deficits in adult Ts65Dn mice [19]. Altogether, these findings suggest that treatment with $\mathrm{GABA}_{\mathrm{A}}$ receptor antagonists leads to long-lasting effects in synaptic plasticity, learning and memory in Ts65Dn mice, and they suggest that similar treatments may also be effective in Down syndrome. It is important to note, however, that this type of therapeutic strategy could be problematic in the case of neurodevelopmental disorders with increased susceptibility for seizures. $\mathrm{GABA}_{\mathrm{A}}$ receptor antagonists may also have negative anxiogenic effects. Thus, it may be important to develop diagnostic tools for individualized medicine approaches that identify individuals that could benefit from specific therapeutic approaches, such as $\mathrm{GABA}_{\mathrm{A}}$ receptor antagonists.

Unlike the case with $\mathrm{NfI}^{+-}$mice, where treatment with picrotoxin had a more immediate effect on learning [14], in the Ts65Dn mice this effect was delayed $[18,19]$. This is puzzling since $\mathrm{GABA}_{\mathrm{A}}$ receptor antagonists have an immediate effect on inhibition. This unexplained delayed therapeutic action is not unlike other psychopharmacological effects, such as the well-characterized delayed effect of antidepressants. One possibility is that treatment with GABA receptor inhibitors, and the resulting lowering of inhibitory tone, could reactivate latent developmental plasticity processes $[20,21]$, and therefore lead to the restoration of LTP and learning in the Ts65Dn mice. If this were true, the same treatment could be used in a wide range of conditions.

Although considerably less common than Down syndrome, Rubinstein-Taybi Syndrome (RTS) is another genetic disorder also characterized by intellectual disability and characteristic changes in physical features [22]. Mutations in several genes, including the CREB binding protein $(C B P)$, are known to cause this syndrome [23]. Increases in cAMP triggered by learning are thought to activate transcription regulated by both CBP and CREB. CBP is also known to have histone acetyltransferase activity. Previous studies implicated CBP in transcriptional responses required for long-term memory [24, 25]. Accordingly, studies with context fear conditioning and object 
recognition showed that a mouse model of RTS $\left(\mathrm{Cbp}^{+-}\right.$ mice) has normal short-term memory, but impaired longterm memory [26, 27]. Importantly, the memory deficits of these mutants could be treated in adult mice with pharmacological strategies that enhance CREB dependent gene expression. For example, SAHA, an histone deacetylase (HDAC) inhibitor was shown to improve context fear memory in $\mathrm{Cbp}^{+-}$mice [27]. Similarly, treatments with phospodiesterase-4 (PDE-4) inhibitors given to adult mutants also resulted in long-term memory improvements [26]. PDE-4 inhibitors block the breakdown of cAMP and presumably enhance PKA-dependent activation of CREB. Consequently, it is possible that similar treatments may also help RTS individuals. It is important to note that both HDAC and PDE-4 inhibitors are known to improve longterm memory in wild-type mice. Again, clinical application of these approaches will require a great deal of caution, since both of these inhibitors, especially when given to pregnant mothers or young children, may have serious side effects.

Tuberous sclerosis complex (TSC) is another example of a neurodevelopmental disorder where treatment of the primary biochemical deficits in adult mice resulted in clear improvement of cognitive phenotypes. TSC is associated with intellectual disability, autism, epilepsy, ADHD and specific learning disabilities [28, 29]. This disorder is caused by heterozygous mutations in either the TSC1 or the TSC2 genes [30, 31]. Although tubers and early onset seizures account only partially for the variability in IQ in TSC subjects [32], these and other developmental brain abnormalities were traditionally thought to be the cause of cognitive impairments [32, 33].

In mouse models of TSC, however, recent studies demonstrated learning and memory deficits in the absence of tubers or spontaneous seizures [34, 35]. Mechanistic studies in mice heterozygous for a null mutation of the $T s c 2$ gene $\left(T s c 2^{+-}\right)$suggested that the learning and memory deficits in these mice are caused by abnormalities in LTP due to enhancements in mTOR signaling. The proteins encoded by the $T_{s c 1}$ and $T_{s c 2}$ genes serve as a GTPase activating protein complex (GAP) that modulates mTOR signaling. The increase in mTOR signaling appeared to change the threshold for the induction of the late-phase of LTP. Conditions that normally induce only a short-lived early-phase of LTP in controls, triggered instead an abnormally stable LTP in $T s c 2^{+/-}$mice [35]. Such inappropriate stabilization of plasticity may degrade the specificity of synaptic modifications that occur during normal learning, thereby leading to memory impairments. Remarkably, decreasing mTOR signaling in adult $T s c 2^{+/-}$mice with a brief treatment of rapamycin, an FDA-approved drug, rescued the context discrimination, spatial learning and LTP abnormalities of these mutants [35]. These results demonstrated that the learning and memory impairments in $T s c 2^{+-}$mice were not caused by irreversible developmental deficits, and that instead they were likely due to abnormally high mTOR signaling in adults [35].

Even though mice heterozygous for TSC genes do not show either cortical tubers or spontaneous seizures [34, 35], homozygous TSC mutants have a more severe phenotype that includes seizures, neurological impairments and lethality. Importantly, these phenotypes were also rescued by rapamycin [35-37]. Inhibitors of mTOR signaling, however, did not reverse abnormal orientation of apical dendrites in layer V of the somatosensory cortex [36], suggesting that full reversal of TSC neurodevelopmental phenotypes may not be possible, or that TSC may lead to changes in signaling that rapamycin cannot reverse.

Like TSC, mutations in PTEN (phosphatase and tensin homolog deleted on chromosome ten) are also associated with autism [38-40]. In addition, mutations in this gene can lead to Lhermitte-Duclos disease (associated with intellectual disability, ataxia, cerebellar ganglion cell hypertrophy and seizures) and Cowden syndrome (a multiple hamartoma syndrome). PTEN regulates phosphatidylinositol-3 kinase (PI3K) upstream of TSC-mTOR signaling. Studies with Pten mutant mice have also documented surprising recovery of behavioral and neurological impairment in adult animals after disease onset [41, 42]. Inhibition of mTOR with rapamycin has been found to reduce anxiety, improve social activity, and control seizures in mutant mice with a neuronal-specific homozygous Pten mutation, even when treatment was initiated in adult animals [41, 42]. The cluster of neurological abnormalities, behavioral changes and seizures in Pten mutant mice is significant because it is reminiscent of phenotypes associated with autism in patients. Importantly, brain macrocephaly, anxiety, social impairments and epilepsy, all phenotypes commonly associated with autism, are either partially or completely treated with rapamycin, even when treatment is initiated in adult mice $[41,42]$. It is possible that targeting a single pathway will not be sufficient to reverse key phenotypes, such as brain macrocephaly, anxiety, social impairments and epilepsy. Instead, a combined therapy that targets key signaling pathways disrupted may be more efficacious. For example, PTEN also regulates GSK-3 signaling and it is possible that therapies that target both GSK-3 and mTOR signaling would be more efficacious.

The PI3K/AKT/TSC pathway is a key pathway controlling protein synthesis and brain growth, and disruptions in this pathway could lead to developmental abnormalities associated with (and perhaps causing) autism [43]. Accordingly, mutations in PTEN and TSC genes have been associated with macrocephaly in humans and mice. A treatment with rapamycin started at 10-12 weeks of age and lasting for 4-6 weeks, reversed macrocephaly and neuronal 
hypertrophy as well as resulted in significant structural neuroanatomical recovery in Pten mutant mice [42]. However remarkable, it is important to point out that this recovery was not complete since some abnormalities remained, including compression of the CA1 region. As with the TSC mutant mice, rapamycin resulted in dramatic improvements of already established morphological abnormalities, but not in complete reversal of these abnormalities. Altogether the studies reviewed demonstrate that pathological alterations in PI3K/AKT/TSC/mTOR signaling result in neurodevelopmental deficits, many of which could be reversed with pharmacological treatments in adults.

As with PI3K/AKT/TSC/mTOR signaling disorders, mutations in the gene causing Fragile X syndrome (FXS), a neurodevelopmental disorder, are also associated with mRNA translation abnormalities and autism. Additionally, this X-linked disorder also includes learning disabilities, intellectual disability, ADHD and epilepsy [44]. CGG triplet repeat-expansions in the $5^{\prime}$ untranslated region of the FMRI gene are thought to lead to hypermethylation which blocks transcription of the FMR1 gene, and a reduction in the FMR protein (FMRP). FMRP is an RNAbinding protein involved in the local regulation of protein synthesis downstream of mGluR signaling, thereby contributing to the control of spine morphology and synaptic function [45]. Specifically, increased group I mGluR signaling appears to play a central role in the pathophysiology of FXS, including associated cognitive dysfunction [46, 47], since a $m$ GluR5 germ-line heterozygous mutation rescued a wide range of behavioral and physiological phenotypes in the Fmrl knockout mouse model of FXS. This demonstrates that mGluR signaling plays an important role in the phenotypes of these mice [46].

Remarkably, mGluR antagonists rescued defective courtship behavior, impaired memory in a conditioned courtship task and CNS structural brain abnormalities in a Drosophila model of FXS [48]. Although treatment given specifically during development rescued abnormal courtship behavior, memory impairments and neuroanatomical defects in mushroom bodies in adult FXS flies, adult treatment only rescued partially the abnormal courtship behavior and the memory impairments. Adult treatment also did not reverse structural brain abnormalities in mushroom bodies of adult FXS flies. Interestingly, the same treatment with mGluR antagonists that helped FXS flies, led to deficits in wildtype flies, confirming the specificity of the mechanisms targeted. These results suggest that abnormal courtship behavior and memory impairments observed in adult FXS flies are caused by abnormal mGluR signaling during both development and in adulthood. Again, rescue of the signaling deficits in either development or adulthood resulted in significant rescue of the behavioral impairments.
Studies in mice have also provided evidence that acute pharmacological treatment with mGluR5 antagonists in adults ameliorated some of the phenotypes associated with FXS, including audiogenic seizures and open field behavioral abnormalities [49, 50].

Another potential treatment strategy for FXS is to block excessive protein synthesis downstream of mGluR signaling. In fact, adult treatment of FXS mutant flies with the protein synthesis inhibitors puromycin or cycloheximide restored memory impairments [51]. Protein synthesis inhibitors were also effective against epileptic activity in Fmrl knockout mice [52]. These findings [51, 52] and others reviewed above $[35,41,42]$ indicate that disinhibited translational control in the mature nervous system contributes to cognitive and neurological symptoms in autismassociated genetic disorders, such as TSC and FXS.

Pilot clinical trials suggest that reversing mGluR5 signaling deficits may also ameliorate FXS phenotypes in adult patients. For example, a pilot, open label trial suggested that lithium seemed to improve 5 different outcome measures in FXS individuals [53]. However, it is difficult to interpret these findings because these results could have been due to placebo effects unfortunately common in clinical trials with cognitive and behavioral outcomes [15, 54]. Similar concerns affect the interpretation of a pilot open-label, single-dose trial of fenobam, an mGluR5 antagonist, where a single oral dose appeared to result in improved pre-pulse inhibition (PPI) [55]. Nevertheless, the studies in flies, mice and FXS individuals suggest that increases in mGluR5 signaling contribute to the FXS phenotype, and that adult interventions that decrease these signaling abnormalities have considerable potential in treating FXS.

Rett syndrome [56] is another X-linked developmental genetic disorder associated with autistic phenotypes including repetitive behaviors, impaired sociability, language and communication problems. Motor symptoms, such as developmental delay or even difficulties in walking, spasticity, ataxia, hypotonia, respiratory dysfunction, dystonia, chorea, as well as intellectual disability and seizures are also common in Rett syndrome. This disorder affects primarily girls and is caused by mutations in a X-chromosomal gene that encodes the transcriptional regulator MeCP2 [57]. This protein modulates the expression of a large number of other genes and it appears to act both as a transcription activator and repressor [58]. Mecp 2 expression is restricted to neuronal lineage cells and becomes more pronounced with neuronal maturation [59].

Rett syndrome mouse models have been generated with deletions of murine Mecp2 [60-62]. The deletion of Mecp2 in male mice causes high mortality and progressive neurological disease, including gait abnormalities, respiratory dysfunction, and hind limb clasping. Although milder, 
female mutant mice also show neurological impairments that do not appreciably reduce survival. Mecp 2 mutant mice also have decreased neuronal arborization that appears to be the cause for their lower brain volumes.

Recently, an elegant series of experiments using the CreloxP genetic strategy looked at the consequences of restoring normal Mecp2 gene function at various ages [63]. In these experiments the Меср2 gene was silenced with a lox-STOP cassette that was deleted at different developmental ages, thus restoring gene function. The deletion was carried out with a fusion protein between the Cre recombinase that recognizes the lox sites and a mutated form of the ligand binding domain of the estrogen receptor that renders Cre activity tamoxifen inducible. The analysis of a number of phenotypes caused by the Mecp 2 mutation, including hind limb clasping, inertia, irregular breathing, gait, and tremor, showed that these phenotypes were not irreversible even in adults. Accordingly, restoring Mecp2 expression in mature female mutant mice, after onset of neurological disease, reversed function to wild-type levels and restored proper levels of neuronal plasticity. Interestingly, sudden restoration of Mecp 2 function actually caused death in half of the mice treated, while a more gradual reexpression schedule did not. This result suggests that the dynamic (although precarious) biochemical balance established in mutant mice had to be reversed in a progressive gradual manner. Additionally, it is important to note that restoration of normal Mecp2 expression only took place in approximately $80 \%$ of cells, demonstrating that complete reversal is not needed for significant gains in function. This is a key result with significant repercussions for possible future clinical studies with viral vectors where only a subset of cells may be expected to be transfected. These fascinating findings demonstrate that deficits caused by loss of Mecp 2 function in development do not result in irrevocable impairments. Instead, reversing the cause for the neurodevelopmental deficits in adults can restore function (at least partially).

Interestingly, a common theme in many of the genetic disorders reviewed here is a change in the ratio between excitation and inhibition. For example, this ratio was decreased in the neocortex of Mecp2 mutant mice [64]; in Fragile $\mathrm{X}$ mice this ratio was increased due to reduced excitatory drive to inhibitory neurons [65]. As discussed above, both NF1 and Down syndrome mouse models showed higher levels of inhibition but normal excitation $[13,14,17]$. Altogether, the analyses of these and other models [66] suggest that a change in the balance between excitation and inhibition is an important feature of neurodevelopmental disorders [67].

What could be the reasons for this surprising rescue of cognitive function in mouse models of neurodevelopmental disorders? One possibility is that unlike humans, in mice these disorders have only a minor neurodevelopmental component. This is unlikely, since there is extensive evidence for the involvement of the disrupted signaling pathways in development. Additionally, in some of the cases described (e.g. Mecp2), there was direct evidence for developmental changes that were later reversed or ameliorated in adults. Another possibility is that there is far more adult plasticity than it was previously suspected [20, 21, 68-70], and that these mechanisms are engaged in reversing the neurodevelopmental phenotypes of these models. It is also possible that neurodevelopmental genes also have functions in adults (e.g., DISC1, NF1, TSC, Fragile $\mathrm{X}$, etc.) and once the primary biochemical deficit is corrected in adults, latent neurodevelopmental mechanisms for cellular, structural and behavioral plasticity are responsible for recovery of function. Whatever the mechanism, these studies strongly indicate that rescuing the underlying mechanisms in adults can result in substantial improvements in function. Although it is unclear whether the dramatic rescues reviewed here will extend to humans, or whether they will apply to other neurodevelopmental disorders, they add considerable credibility to the dream that one day we may have adult treatments for the many millions of people affected by neurodevelopmental disorders, such as autism.

Acknowledgements This work was supported by the following grants: EH223/2-1 to D.E., and NIH R01-NS38480 and P50MH0779720 to A.J.S.

Open Access This article is distributed under the terms of the Creative Commons Attribution Noncommercial License which permits any noncommercial use, distribution, and reproduction in any medium, provided the original author(s) and source are credited.

\section{References}

1. Ehninger D, Li W, Fox K, Stryker MP, Silva AJ. Reversing neurodevelopmental disorders in adults. Neuron. 2008;60:950-960.

2. Hanley WB. Adult phenylketonuria. Am J Med. 2004;117:590-595.

3. Rovet J, Daneman D. Congenital hypothyroidism: a review of current diagnostic and treatment practices in relation to neuropsychologic outcome. Paediatr Drugs. 2003;5:141-149.

4. Zoeller RT, Rovet J. Timing of thyroid hormone action in the developing brain: clinical observations and experimental findings. J Neuroendocrinol. 2004;16:809-818.

5. Dugbartey AT. Neurocognitive aspects of hypothyroidism. Arch Intern Med. 1998;158:1413-1418.

6. Davis JD, Tremont G. Neuropsychiatric aspects of hypothyroidism and treatment reversibility. Minerva Endocrinol. 2007;32:49-65.

7. Kolb B, Gibb R, Gorny G. Cortical plasticity and the development of behavior after early frontal cortical injury. Dev Neuropsychol. 2000;18:423-444.

8. Vannucci SJ, Hagberg H. Hypoxia-ischemia in the immature brain. J Exp Biol. 2004;207:3149-3154. 
9. Li W, Zhou Y, Jentsch JD, Brown RA, Tian X, Ehninger D, et al. Specific developmental disruption of disrupted-in-schizophrenia-1 function results in schizophrenia-related phenotypes in mice. Proc Natl Acad Sci U S A. 2007;104:18280-18285.

10. Mao Y, Ge X, Frank CL, Madison JM, Koehler AN, Doud MK, et al. Disrupted in schizophrenia 1 regulates neuronal progenitor proliferation via modulation of GSK3beta/beta-catenin signaling. Cell. 2009;136:1017-1031.

11. Silva AJ, Frankland PW, Marowitz Z, Friedman E, Laszlo GS, Cioffi D, et al. A mouse model for the learning and memory deficits associated with neurofibromatosis type I. Nat Genet. 1997;15:281-284.

12. Li W, Cui Y, Kushner SA, Brown RA, Jentsch JD, Frankland PW, et al. The HMG-CoA reductase inhibitor lovastatin reverses the learning and attention deficits in a mouse model of neurofibromatosis type 1. Curr Biol. 2005;15:1961-1967.

13. Costa RM, Federov NB, Kogan JH, Murphy GG, Stern J, Ohno $\mathrm{M}$, et al. Mechanism for the learning deficits in a mouse model of neurofibromatosis type 1. Nature. 2002;415:526-530.

14. Cui Y, Costa RM, Murphy GG, Elgersma Y, Zhu Y, Gutmann DH, et al. Neurofibromin regulation of ERK signaling modulates GABA release and learning. Cell. 2008;135:549-560.

15. Krab LC, de Goede-Bolder A, Aarsen FK, Pluijm SM, Bouman MJ, van der Geest JN, et al. Effect of simvastatin on cognitive functioning in children with neurofibromatosis type 1: a randomized controlled trial. Jama. 2008;300:287-294.

16. Reeves RH, Irving NG, Moran TH, Wohn A, Kitt C, Sisodia SS, et al. A mouse model for Down syndrome exhibits learning and behaviour deficits. Nat Genet. 1995;11:177-184.

17. Kleschevnikov AM, Belichenko PV, Villar AJ, Epstein CJ, Malenka RC, Mobley WC. Hippocampal long-term potentiation suppressed by increased inhibition in the Ts65Dn mouse, a genetic model of Down syndrome. J Neurosci. 2004;24:8153-8160.

18. Fernandez F, Morishita W, Zuniga E, Nguyen J, Blank M, Malenka $\mathrm{RC}$, et al. Pharmacotherapy for cognitive impairment in a mouse model of Down syndrome. Nat Neurosci. 2007;10:411-413.

19. Rueda N, Florez J, Martinez-Cue C. Chronic pentylenetetrazole but not donepezil treatment rescues spatial cognition in Ts65Dn mice, a model for Down syndrome. Neurosci Lett. 2008;433:22-27.

20. Hensch TK, Fagiolini M, Mataga N, Stryker MP, Baekkeskov S, Kash SF. Local GABA circuit control of experience-dependent plasticity in developing visual cortex. Science. 1998;282:1504-1508.

21. Pizzorusso T, Medini P, Berardi N, Chierzi S, Fawcett JW, Maffei L. Reactivation of ocular dominance plasticity in the adult visual cortex. Science. 2002;298:1248-1251.

22. Rubinstein JH, Taybi H. Broad thumbs and toes and facial abnormalities. A possible mental retardation syndrome. Am J Dis Child. 1963;105:588-608.

23. Petrij F, Giles RH, Dauwerse HG, Saris JJ, Hennekam RC, Masuno $\mathrm{M}$, et al. Rubinstein-Taybi syndrome caused by mutations in the transcriptional co-activator CBP. Nature. 1995;376:348-351.

24. Lonze BE, Ginty DD. Function and regulation of CREB family transcription factors in the nervous system. Neuron. 2002;35:605-623.

25. Hallam TM, Bourtchouladze R. Rubinstein-Taybi syndrome: molecular findings and therapeutic approaches to improve cognitive dysfunction. Cell Mol Life Sci. 2006;63:1725-1735.

26. Bourtchouladze R, Lidge R, Catapano R, Stanley J, Gossweiler S, Romashko D, et al. A mouse model of Rubinstein-Taybi syndrome: defective long-term memory is ameliorated by inhibitors of phosphodiesterase 4. Proc Natl Acad Sci U S A. 2003;100:10518-10522.

27. Alarcon JM, Malleret G, Touzani K, Vronskaya S, Ishii S, Kandel ER, et al. Chromatin acetylation, memory, and LTP are impaired in $\mathrm{CBP}+/-$ mice: a model for the cognitive deficit in RubinsteinTaybi syndrome and its amelioration. Neuron. 2004;42:947-959.

28. Joinson C, O'Callaghan FJ, Osborne JP, Martyn C, Harris T, Bolton PF. Learning disability and epilepsy in an epidemiological sample of individuals with tuberous sclerosis complex. Psychol Med. 2003;33:335-344.

29. de Vries P, Humphrey A, McCartney D, Prather P, Bolton P, Hunt A. Consensus clinical guidelines for the assessment of cognitive and behavioural problems in Tuberous Sclerosis. Eur Child Adolesc Psychiatry. 2005;14:183-190.

30. Consortium ECTS. Identification and characterization of the tuberous sclerosis gene on chromosome 16. Cell. 1993;75:13051315.

31. van Slegtenhorst M, de Hoogt R, Hermans C, Nellist M, Janssen $\mathrm{B}$, Verhoef $\mathrm{S}$, et al. Identification of the tuberous sclerosis gene TSC1 on chromosome 9q34. Science. 1997;277:805-808.

32. O'Callaghan FJ, Harris T, Joinson C, Bolton P, Noakes M, Presdee D, et al. The relation of infantile spasms, tubers, and intelligence in tuberous sclerosis complex. Arch Dis Child. 2004;89:530-533.

33. Raznahan A, Higgins NP, Griffiths PD, Humphrey A, Yates JR, Bolton PF. Biological markers of intellectual disability in tuberous sclerosis. Psychol Med. 2007;37:1293-1304.

34. Goorden SM, van Woerden GM, van der Weerd L, Cheadle JP, Elgersma Y. Cognitive deficits in Tsc1+/- mice in the absence of cerebral lesions and seizures. Ann Neurol. 2007;62:648-655.

35. Ehninger D, Han S, Shilyansky C, Zhou Y, Li W, Kwiatkowski DJ, et al. Reversal of learning deficits in a Tsc2+/- mouse model of tuberous sclerosis. Nat Med. 2008;14:843-848.

36. Meikle L, Pollizzi K, Egnor A, Kramvis I, Lane H, Sahin M, et al. Response of a neuronal model of tuberous sclerosis to mammalian target of rapamycin (mTOR) inhibitors: effects on mTORC1 and Akt signaling lead to improved survival and function. J Neurosci. 2008;28:5422-5432.

37. Zeng LH, Xu L, Gutmann DH, Wong M. Rapamycin prevents epilepsy in a mouse model of tuberous sclerosis complex. Ann Neurol. 2008;63:444-453.

38. Marsh DJ, Kum JB, Lunetta KL, Bennett MJ, Gorlin RJ, Ahmed $\mathrm{SF}$, et al. PTEN mutation spectrum and genotype-phenotype correlations in Bannayan-Riley-Ruvalcaba syndrome suggest a single entity with Cowden syndrome. Hum Mol Genet. 1999;8:1461-1472.

39. Goffin A, Hoefsloot LH, Bosgoed E, Swillen A, Fryns JP. PTEN mutation in a family with Cowden syndrome and autism. Am J Med Genet. 2001;105:521-524.

40. Butler MG, Dasouki MJ, Zhou XP, Talebizadeh Z, Brown M, Takahashi TN, et al. Subset of individuals with autism spectrum disorders and extreme macrocephaly associated with germline PTEN tumour suppressor gene mutations. J Med Genet. 2005;42:318-321.

41. Kwon CH, Zhu X, Zhang J, Baker SJ. mTor is required for hypertrophy of Pten-deficient neuronal soma in vivo. Proc Natl Acad Sci U S A. 2003;100:12923-12928.

42. Zhou J, Blundell J, Ogawa S, Kwon CH, Zhang W, Sinton C, et al. Pharmacological inhibition of mTORC1 suppresses anatomical, cellular, and behavioral abnormalities in neural-specific Pten knock-out mice. J Neurosci. 2009;29:1773-1783.

43. Courchesne E, Pierce K, Schumann CM, Redcay E, Buckwalter JA, Kennedy DP, et al. Mapping early brain development in autism. Neuron. 2007;56:399-413.

44. Hagerman RJ, Hagerman PJ. The fragile X premutation: into the phenotypic fold. Curr Opin Genet Dev. 2002;12:278-283.

45. Bassell GJ, Warren ST. Fragile X syndrome: loss of local mRNA regulation alters synaptic development and function. Neuron. 2008;60:201-214.

46. Bear MF, Huber KM, Warren ST. The mGluR theory of fragile X mental retardation. Trends Neurosci. 2004;27:370-377.

47. Dolen G, Osterweil E, Rao BS, Smith GB, Auerbach BD, Chattarji $\mathrm{S}$, et al. Correction of fragile $\mathrm{X}$ syndrome in mice. Neuron. 2007;56:955-962. 
48. McBride SM, Choi CH, Wang Y, Liebelt D, Braunstein E, Ferreiro D, et al. Pharmacological rescue of synaptic plasticity, courtship behavior, and mushroom body defects in a Drosophila model of fragile X syndrome. Neuron. 2005;45:753-764.

49. Yan QJ, Rammal M, Tranfaglia M, Bauchwitz RP. Suppression of two major Fragile X Syndrome mouse model phenotypes by the mGluR5 antagonist MPEP. Neuropharmacology. 2005;49:10531066.

50. de Vrij FM, Levenga J, van der Linde HC, Koekkoek SK, De Zeeuw CI, Nelson DL, et al. Rescue of behavioral phenotype and neuronal protrusion morphology in Fmr1 KO mice. Neurobiol Dis. 2008;31:127-132.

51. Bolduc FV, Bell K, Cox H, Broadie KS, Tully T. Excess protein synthesis in Drosophila fragile $\mathrm{X}$ mutants impairs long-term memory. Nat Neurosci. 2008;11:1143-1145.

52. Chuang SC, Zhao W, Bauchwitz R, Yan Q, Bianchi R, Wong RK. Prolonged epileptiform discharges induced by altered group I metabotropic glutamate receptor-mediated synaptic responses in hippocampal slices of a fragile $\mathrm{X}$ mouse model. J Neurosci. 2005;25:8048-8055.

53. Berry-Kravis E, Sumis A, Hervey C, Nelson M, Porges SW, Weng $\mathrm{N}$, et al. Open-label treatment trial of lithium to target the underlying defect in fragile X syndrome. J Dev Behav Pediatr. 2008;29:293-302.

54. Berry-Kravis E, Krause SE, Block SS, Guter S, Wuu J, Leurgans $\mathrm{S}$, et al. Effect of CX516, an AMPA-modulating compound, on cognition and behavior in fragile $\mathrm{X}$ syndrome: a controlled trial. J Child Adolesc Psychopharmacol. 2006;16:525-540.

55. Berry-Kravis EM, Hessl D, Coffey S, Hervey C, Schneider A, Yuhas $\mathrm{J}$ et al.: A pilot open-label single-dose trial of fenobam in adults with fragile X syndrome. J Med Genet, 2009

56. Rett A. On a unusual brain atrophy syndrome in hyperammonemia in childhood. Wien Med Wochenschr. 1966;116:723-726.

57. Amir RE, Van den Veyver IB, Wan M, Tran CQ, Francke U, Zoghbi HY. Rett syndrome is caused by mutations in X-linked MECP2, encoding methyl-CpG-binding protein 2. Nat Genet. 1999;23:185-188.

58. Chahrour M, Jung SY, Shaw C, Zhou X, Wong ST, Qin J, et al. $\mathrm{MeCP} 2$, a key contributor to neurological disease, activates and represses transcription. Science. 2008;320:1224-1229.
59. Kishi N, Macklis JD. MECP2 is progressively expressed in postmigratory neurons and is involved in neuronal maturation rather than cell fate decisions. Mol Cell Neurosci. 2004;27:306-321.

60. Chen RZ, Akbarian S, Tudor M, Jaenisch R. Deficiency of methyl-CpG binding protein-2 in CNS neurons results in a Rettlike phenotype in mice. Nat Genet. 2001;27:327-331.

61. Guy J, Hendrich B, Holmes M, Martin JE, Bird A. A mouse Mecp2-null mutation causes neurological symptoms that mimic Rett syndrome. Nat Genet. 2001;27:322-326.

62. Shahbazian M, Young J, Yuva-Paylor L, Spencer C, Antalffy B, Noebels J, et al. Mice with truncated MeCP2 recapitulate many Rett syndrome features and display hyperacetylation of histone H3. Neuron. 2002;35:243-254.

63. Guy J, Gan J, Selfridge J, Cobb S, Bird A. Reversal of neurological defects in a mouse model of Rett syndrome. Science. 2007;315:1143-1147.

64. Dani VS, Chang Q, Maffei A, Turrigiano GG, Jaenisch R, Nelson SB. Reduced cortical activity due to a shift in the balance between excitation and inhibition in a mouse model of Rett syndrome. Proc Natl Acad Sci U S A. 2005;102:12560-12565.

65. Gibson JR, Bartley AF, Hays SA, Huber KM. Imbalance of neocortical excitation and inhibition and altered UP states reflect network hyperexcitability in the mouse model of fragile $\mathrm{X}$ syndrome. J Neurophysiol. 2008;100:2615-2626.

66. Tabuchi K, Blundell J, Etherton MR, Hammer RE, Liu X, Powell CM, et al. A neuroligin-3 mutation implicated in autism increases inhibitory synaptic transmission in mice. Science. 2007;318:71-76.

67. Rubenstein JL, Merzenich MM. Model of autism: increased ratio of excitation/inhibition in key neural systems. Genes Brain Behav. 2003;2:255-267.

68. Sale A, Maya Vetencourt JF, Medini P, Cenni MC, Baroncelli L, De Pasquale R, et al. Environmental enrichment in adulthood promotes amblyopia recovery through a reduction of intracortical inhibition. Nat Neurosci. 2007;10:679-681.

69. Maya Vetencourt JF, Sale A, Viegi A, Baroncelli L, De Pasquale $\mathrm{R}$, O'Leary $\mathrm{OF}$, et al. The antidepressant fluoxetine restores plasticity in the adult visual cortex. Science. 2008;320:385-388.

70. Spolidoro M, Sale A, Berardi N, Maffei L: Plasticity in the adult brain: lessons from the visual system. Exp Brain Res, 2008 